\title{
Desempenho agronômico e qualidade de sementes de cultivares de feijão-caupi na região do cerrado ${ }^{1}$
}

\author{
Agronomic performance and quality of seeds of cowpea cultivar in the brazilian \\ "cerrado" region
}

\author{
Itamar Rosa Teixeira ${ }^{2 *}$, Gisele Carneiro da Silva ${ }^{3}$, João Paulo Ribeiro de Oliveira ${ }^{4}$, Alessandro Guerra da Silva ${ }^{5}$ \\ e Adilson Pelá ${ }^{6}$
}

\begin{abstract}
Resumo - As produções de feijão-caupi, atualmente, no Brasil, são baixas em função, especialmente, do uso de materiais de baixa capacidade produtiva, associado à utilização de sementes de baixa qualidade. Assim, objetivou-se com este trabalho avaliar as características agronômicas e qualidade fisiológica de sementes de diferentes cultivares de caupi nas condições edafoclimáticas do cerrado goiano. Empregou-se o delineamento de blocos casualizados com quatro repetições. Os tratamentos foram constituídos por oito cultivares de caupi (BRS Guariba, BRS 17 Gurguéia, BRS Rouxinol, BRS Marataoã, Patativa, BRS Tracuateua, BRS Milênio e CE 315), recomendados para as regiões Norte e Nordeste do Brasil. O efeito dos tratamentos foram significativos para todos os caracteres avaliados. As cultivares BRS Guariba, BRS 17 Gurguéia e BRS Marataoã apresentaram menores problemas com oídio. Os genótipos de caupi mais produtivos foram BRS Guariba e BRS Gurguéia, com 2.211 e $2.196 \mathrm{~kg} \mathrm{ha}^{-1}$ de grãos, respectivamente. A qualidade fisiológica de sementes de caupi foi influenciada pelas cultivares testadas. As cultivares de tegumento colorido caupi CE 315, BRS Gurguéia, BRS Rouxinol, BRS Marataoã e Patativa produziram sementes de melhor qualidade fisiológica, comparativamente, com as cultivares de tegumento branco BRS Tracuateua, BRS Milênio e BRS Guariba.
\end{abstract}

Palavras-chave - Vigna unguiculata L. Walp. Interação genótipos com ambiente. Germinação. Cultivos agrícolas-rendimento. Semente-qualidade.

\begin{abstract}
The productivities of cowpea are low, depending on the use of low productivity capacity cultivar planted, associated with the use of low-quality seeds. The objective of this work was to evaluate the agronomic characteristics and physiological quality in seed lots of different cultivar of cowpea in the "Cerrado", Goiás State, Brazil. The experimental design was a complete block with four replicates. The treatments were eight cultivar of cowpea (BRS Guariba, BRS 17 Gurguéia, BRS Rouxinol, BRS Marataoã, Patativa, BRS Tracuateua, BRS Milênio e CE 315), recommended for the North and Northeast regions of Brazil. The effects of the treatments were considerable for all the characteristics assessed. The cultivar BRS Guariba, BRS 17 Gurguéia and BRS Marataoã, presented less intense powdery mildew symptoms. The cultivar presenting higher yield were BRS Guariba and BRS Gurguéia, with 2,211 and 2,196 $\mathrm{kg} \mathrm{ha}^{-1}$ of grain, respectively. The results showed that physiological seed quality influenced productivity of the cultivar. The cultivar BRS CE 315, BRS Gurguéia, BRS Rouxinol, BRS Marataoã and Patativa, with colored hull, produced seeds of better physiological quality compared, to the cultivar of white hull BRS Tracuateua, BRS Milênio and BRS Guariba.
\end{abstract}

Key words - Vigna unguiculata L. Walp. Genotype with environment interaction. Yield. Germination. Cropping systemsyield. Seed-quality.

\footnotetext{
* Autor para correspondência

${ }^{1}$ Recebido para publicação em 16/09/2009; aprovado em 27/04/2010

Pesquisa financiada pela Universidade Estadual de Goiás, UnUCET

${ }^{2}$ Universidade Estadual de Goiás, UnUCET, BR 153, Km 98, Anápolis-GO, Brasil, 75.001-970, itamar.texeira@ueg.br

${ }^{3}$ Programa de Pós-Graduação em Agronomia, Universidade Federal de Goiás, Rodovia Goiânia Nova Veneza, Km 0, Campus Samambaia, GoiâniaGO, Brasil, 74.001-270, gisele.carneiro@hotmail.com

${ }^{4}$ Programa de Pós-Graduação em Produção Vegetal, Universidade Federal de Uberlândia, Campus Umuarama, Uberlândia-MG, Brasil, 38.400-902, oliveira.jpr@hotmail.com

${ }^{5}$ Depto de Agronomia, Universidade de Rio Verde, Rio Verde-GO, Brasil, 75.901-970, silvaag@yahoo.com.br

${ }^{6}$ Universidade Estadual de Goiás, UnUIpameri, GO 330, Km 98, Anel Viário, Ipameri-GO, Brasil, 75.780-000, adilson.pela@ueg.br
} 


\section{Introdução}

O feijão-caupi (Vigna unguiculata L. Walp.) possui ainda denominações de feijão-de-corda, feijão-macassar e feijão-fradinho (grãos brancos), representando atualmente $15 \%$ da produção de feijão no Brasil. É cultivado sobretudo nas regiões Norte (55,8 mil hectares) e Nordeste (1,2 milhão de hectare) (SILVA, 2009), sendo o prato básico das classes de menor poder aquisitivo (TEÓFILO et al., 2008), como grão seco para consumo humano, especialmente.

A produção nacional, anualmente, situa-se em torno de 482 mil toneladas (SILVA, 2009), sendo Piauí, Ceará e Bahia os maiores produtores nacionais dessa leguminosa, onde predomina limitações de disponibilidade hídrica, condição esta que caupi se adapta muito bem pela sua rusticidade. Porém, se adapta também ao clima quente e úmido como da região Norte (BEZERRA et al., 2008).

Embora considerada uma cultura tropical com ampla adaptação aos mais diversos ambientes, o caupi ainda apresenta baixos patamares de produtividade (300 kg ha-1) (LEITE et al., 2009) e, dentre as principais causas, é apontada a utilização de baixo nível tecnológico na atividade associado ao uso de cultivares tradicionais com baixo potencial produtivo (CARDOSO; RIBEIRO, 2006). Para Oliveira et al. (2002), no Brasil existe cultivares com boa aceitação comercial, todavia, não há programa de melhoramento objetivando a avaliação e recomendação em ambientes específicos como nas áreas do Centro-Oeste, onde a cultura encontra-se em franca expansão e atualmente sob moldes de agricultura empresarial, cuja lavoura é totalmente mecanizada.

A escolha correta da cultivar para um determinado ambiente e sistema de produção é de grande importância para a obtenção de boa produtividade. Contudo, isso por si só não é suficiente para o sucesso da exploração. É necessário, também, que a cultivar tenha características de grão e de vagem que atendam as exigências de comerciantes e consumidores (VIEIRA, 2001). Outros aspectos importantes tais como ciclo, arquitetura de planta e reações a doenças devem ser levados em consideração, bem como a qualidade das sementes produzidas que, no caso do caupi, pouco se conhece ainda.

Nesse contexto, destaca-se a existência de variabilidade genética para qualidade de sementes entre genótipos de caupi, conforme constatado em trabalho de Almeida et al. (2004), em que foi observado que a cultivar Rabo de Tatu produziu sementes de qualidade inferior comparativamente a cultivar Cedinha, quando submetidas aos efeitos dos impactos impostos durante o beneficiamento.

Para Damião Filho e Môro (2001), a produção agrícola nunca é superior à capacidade da semente utilizada, ou seja, nenhum trato cultural pode melhorar a produção além dos limites genéticos impostos pelo embrião da semente. É essencial, para o aumento da produtividade, que a melhoria do nível tecnológico no cultivo do feijão-caupi esteja associado ao emprego de sementes de alta qualidade. Para Marcos Filho (2005), a utilização de sementes de boa qualidade fisiológica é fator primordial no estabelecimento de qualquer lavoura. Sementes de baixa qualidade, isto é, de potencial de germinação e vigor reduzidos, originam lavouras com baixa população de plantas e em consequência com população inadequada, acarretando sérios prejuízos econômicos.

$\mathrm{Na}$ região Centro-Oeste, especialmente em Goiás, tem-se o hábito de consumir feijão-caupi pelo fato de grande parte de sua população ser formada por povos vindos das regiões Norte e Nordeste, entretanto, nesta região não se produz quantidade suficiente para suprir o mercado consumidor. Ressalta-se que os trabalhos de pesquisa dos órgãos atuantes na região, como a Empresa Brasileira de Pesquisa Agropecuária por meio do Centro Nacional de Pesquisa de Arroz e Feijão, têm concentrado seus esforços em feijão comum (Phaseolus vulgaris L.) e que praticamente são inexistentes trabalhos investigativos com a espécie Vigna unguiculata, onde esta pode se tornar uma boa opção ao cultivo da safrinha em função de sua tolerância ao déficit hídrico, especialmente, a partir de março.

Em função do exposto, objetivou-se com este trabalho avaliar o comportamento agronômico e a qualidade fisiológica de sementes de diferentes cultivares de feijão-caupi nas condições edafoclimáticas do sudeste goiano na safra da seca.

\section{Material e métodos}

O experimento foi conduzido na safra da seca de 2008, em área particular localizada no municipio de Catalão-GO, com as seguintes coordenadas geográficas: $18^{\circ} 10^{\prime} 12^{\prime \prime}$ latitude Sul e 47 $56^{\prime} 31^{\prime \prime}$ longitude Oeste e altitude de $835 \mathrm{~m}$.

O clima da região é classificado, conforme Köppen, como Aw, definido como tropical de verão chuvoso e inverno seco. Os dados climáticos predominantes por ocasião da condução do experimento são mostrados na Figura 1. 


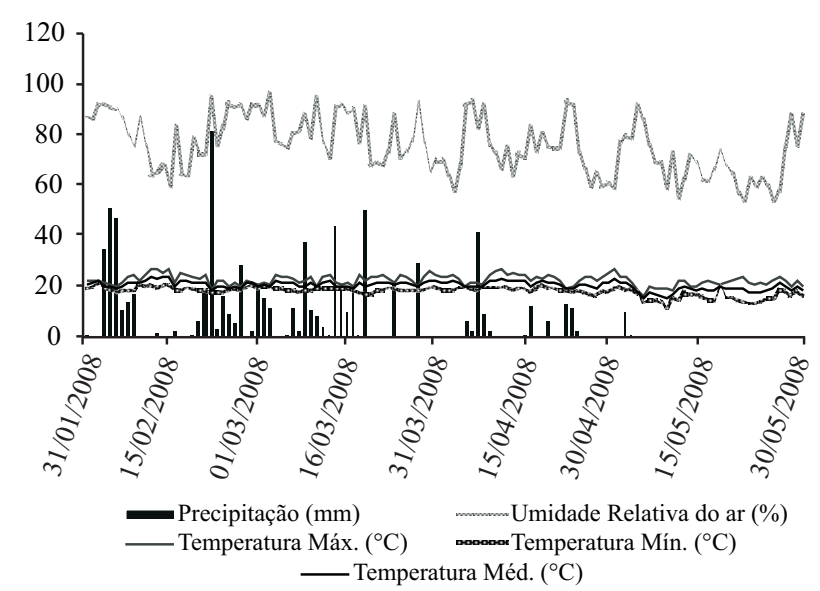

Figura 1 - Variação diária da insolação, umidade relativa, precipitação pluvial e temperatura média no período de fevereiro a maio de 2008. Catalão, GO, 2008

O solo da área foi classificado como Latossolo Vermelho Amarelo eutrófico, argissólico, hipoférrico, fase cerrado, muito profundo e relevo suave ondulado, cujo resultado da análise quimica é apresentado na Tabela 1.
Foi empregado o delineamento de blocos casualizado com quatro repetições. Os tratamentos foram constituídos por oito cultivares de caupi (BRS Guariba, BRS 17 Gurguéia, BRS Rouxinol, BRS Marataoã, Patativa, BRS Tracuateua, BRS Milênio e CE 315), recomendados para cultivo nas regiões Norte e Nordeste. As características mais relevantes de cada cultivar podem ser verificadas na Tabela 2 .

As parcelas foram constituídas de quatro fileiras de 5,0 $\mathrm{m}$ de comprimento, espaçadas de $0,70 \mathrm{~m}$, sendo utilizadas as duas linhas centrais como área útil, eliminando-se 0,50 m de cada lado, a título de bordadura.

Foi realizado o preparo convencional do solo, com uma aração e duas gradagens. A adubação básica foi efetuada empregando o formulado 05-25-20, na dose de $400 \mathrm{~kg} \mathrm{ha}^{-1}$.

A semedura foi efetuada com 15 sementes por metro e, posteriormente, realizado o desbaste, deixandose 10 plantas por metro aos 15 DAE. Aos 25 DAE, foi feita a adubação de $\mathrm{N}$ em cobertura, na dose de $20 \mathrm{~kg} \mathrm{ha}^{-1}$, tendo uréia como fonte. Os demais tratos culturais foram os normalmente aplicados à cultura.

Tabela 1 - Resultado na análise quimica do solo (camada de 0-20 cm) da área experimental

\begin{tabular}{|c|c|c|c|c|c|c|}
\hline $\mathrm{pH}$ & $\mathrm{P}^{(1)}$ & $\mathrm{K}^{(1)}$ & $\mathrm{Ca}^{+3}$ & $\mathrm{Mg}^{+2(2)}$ & $\mathrm{Al}^{3+}$ & $\mathrm{H}^{+}+\mathrm{Al}^{3+}$ \\
\hline$\left(\mathrm{H}_{2} \mathrm{O}\right)$ & \multicolumn{2}{|c|}{$\mathrm{mg} \mathrm{dm}{ }^{-3}$} & \multicolumn{4}{|c|}{$\mathrm{cmol} \mathrm{dm}^{-3}$} \\
\hline 6,0 & 2,0 & 58 & 4,0 & 1,2 & 0,0 & 2,0 \\
\hline $\mathrm{m}$ & $\mathrm{V}$ & $\mathrm{C}^{(3)}$ & $\mathrm{Cu}^{(1)}$ & $\mathrm{Fe}^{(1)}$ & $\mathrm{Mn}^{(1)}$ & $\mathrm{Zn}^{(1)}$ \\
\hline \multicolumn{2}{|c|}{$\%$} & \multicolumn{2}{|c|}{$\mathrm{g} \mathrm{dm}^{-3}$} & \multicolumn{3}{|c|}{$\mathrm{mg} \mathrm{dm}^{-3}$} \\
\hline 0,0 & 65 & 19,0 & 1,5 & 32,0 & 10,2 & 2,1 \\
\hline
\end{tabular}

${ }^{(1)}$ Extrator Mehlich 1; ${ }^{(2)} \mathrm{KCl} 1 \mathrm{~mol} \mathrm{~L}-1 ;{ }^{(3)}$ Método Walkley-Black

Tabela 2 - Algumas características das cultivares de feijão-caupi empregados no estudo. Catalão, GO, 2008

\begin{tabular}{lcccc}
\hline \multicolumn{1}{c}{ Genótipos } & Ciclo (DAE*) & Porte & Peso de 100 grãos (g) & Grupo comercial \\
\hline BRS Guariba & $65-70$ & Semi-ereto & 19,5 & Branco \\
BRS Gurguéia & $70-80$ & Semi-prostrado & 12,5 & Sempre-verde \\
BRS Rouxinol & $65-75$ & Semi-ereto & 17 & Sempre-verde \\
BRS Marataoã & $70-75$ & Semi-prostrado & 15,5 & Sempre-verde \\
Patativa & $65-75$ & Semi-ereto & 19,0 & Marrom-claro \\
BRS Tracuateua & $65-70$ & Prostrado & 28,0 & Branco \\
BRS Milênio & $70-75$ & Prostrado & 23,0 & Branco \\
CE 315 & $64-70$ & Semi-prostrado & 13,0 & Sempre-verde \\
\hline
\end{tabular}

* Dias após emergência - DAE; Fonte: Adaptado da Embrapa (2008) 
Quando necessário, utilizou-se irrigação por aspersão, com turno de rega de 30 minutos com lâmina de água aplicada de $6 \mathrm{~mm}$, duas vezes por semana, de forma a manter o solo com 65 a $70 \%$ da capacidade de campo.

Por ocasião do intenso florescimento da maioria dos genótipos testados, foram realizadas duas avaliações quinzenais, aos 55 e 70 DAE, da severidade de oídio (Erysiple polygoni), com base na escala usada por Vieira et al. (2000): 1 - sem sintoma da doença; 3 - leve; 5 moderada; 7 - severa e 9 - muito severa. As avaliações foram realizadas por três avaliadores, simultaneamente.

$\mathrm{Na}$ maturação, foi avaliado o rendimento de grãos e seus componentes primários (número de vagens por planta, número de grãos por vagem e peso de cem grãos). Os componentes primários foram determinados a partir de amostras aleatórias de 10 plantas, tomadas na área útil de cada parcela, antes da colheita. Já o rendimento de grãos foi avaliado na área útil de cada parcela, sendo o peso originalmente obtido corrigido para $12 \%$ de umidade.

A colheita, manualmente, foi seguida da debulha por meio de batedura, também manual. Após a colheita, amostras de $1,0 \mathrm{~kg}$ de sementes foram coletadas em cada repetição e enviadas ao laboratório para avaliação da qualidade fisiológica, por meio dos seguintes testes: Teste Padrão de Germinação - TPG, primeira contagem do TPG, envelhecimento acelerado e condutividade elétrica.

$\mathrm{O}$ teste de germinação foi realizado com quatro repetições. Sobre três folhas de papel germiteste, umedecidas com água equivalente a 2,5 vezes o seu peso original (seco), foram colocadas 50 sementes/repetição, enroladas e acondicionadas em germinador sob temperatura de $25^{\circ} \mathrm{C}$. A avaliação foi realizada ao $7^{\circ}$ (sétimo) dia após a implantação do teste. Foi computada a porcentagem de plântulas normais (BRASIL, 1992).

Para o teste de primeira contagem de germinação, foram consideradas a porcentagem de plântulas normais presentes no $5^{\circ}$ (quinto) dia após o início do TPG.

Para o envelhecimento acelerado, foram distribuídas 200 sementes/repetição sobre a superfície de uma tela metálica fixada e suspensa no interior de caixa plástica gerbox, contendo $40 \mathrm{~mL}$ de água, mantida a $41^{\circ} \mathrm{C}$ e $100 \%$ de umidade relativa, por 48 horas em um germinador (KRZYZANOWSKI et al., 1999). Decorrido esse período, as sementes foram submetidas ao TPG, anteriormente descrito, no qual determinou-se a porcentagem de plântulas normais no $5^{\circ}$ (quinto) dia após a montagem do teste.

$\mathrm{O}$ teste de condutividade elétrica foi realizado no sistema de copos, conforme a metodologia recomendada por Krzyzanowski et al. (1999), sendo colocado 50 sementes/repetição, previamente pesadas, e colocadas em copos plásticos, contendo $75 \mathrm{~mL}$ de água deionizada, e, em seguida, em um germinador com temperatura de $25^{\circ} \mathrm{C}$ por 24 horas. Decorrido este período, os recipientes foram sendo retirados do germinador e suavemente agitados, e, com o auxílio do aparelho condutivímetro, foi efetuado a medição. Os valores da condutividade elétrica da solução de sementes foram obtidos dividindo-se, para cada repetição, o valor da condutividade lida no condutivímetro $\left(\mu \mathrm{sm}^{-1}\right)$ pelo peso $(\mathrm{g})$ de 100 sementes, sendo seu valor expresso em $\left(\mu \mathrm{S} \mathrm{cm}^{-1} \mathrm{~g}^{-1}\right)$.

A concentração de lignina nas sementes foi determinada pelo método recomendado por Van Soest e Wine (1968), por meio do seguinte procedimento: inicialmente as sementes de cada tratamento foram imersas em água até que fosse possível separar o tegumento dos cotilédones. Posteriormente, os tegumentos foram mantidos em estufa a $80^{\circ} \mathrm{C}$ até atingirem massa constante e resfriados em um dessecador. Duas repetições de $0,3 \mathrm{~g}$ de tegumento por tratamento, previamente moídos, foram utilizadas para determinação da porcentagem de lignina.

Os dados obtidos foram submetidos à análise de variância e, quando detectado diferenças significativas entre os tratamentos, as médias foram comparadas pelo teste de Tukey a $5 \%$ de probabilidade, usando o programa de Análise Estatística e Genética - SAEG.

\section{Resultados e discussão}

\section{Reações às doenças e características agronômicas}

As cultivares de feijão-caupi apresentaram comportamento diferenciado $(\mathrm{P}<0,01)$ pelo teste $\mathrm{F}$ em todas as características avaliadas, o que indica a existência de variabilidade entre os diferentes genótipos estudados. De modo geral, foi detectado boa precisão experimental, conforme os valores dos coeficientes de variação obtidos (Tabela 3), e está de acordo com outros resultados de pesquisa (MATOS FILHO, 2006; ROCHA et al., 2003).

Quanto a doenças, foi detectado somente problema com oídio e, de modo geral, os sintomas começam a aparecer a partir dos $45 \mathrm{DAE}$, coincidente na maioria dos genótipos com a fase de intenso florescimento, certamente por ser esta a fase em que há fechamento da lavoura, e este fato associado a irrigação, favoreceu a existência de microclima favorável a proliferação do patógeno.

Os genótipos que demonstraram maior suscetibilidade ao oídio na presente condição foram CE 315 e Patativa, tanto na primeira como na segunda avaliação. Por outro lado, as cultivares BRS Guariba, BRS Gurguéia e BRS Marataoã demonstraram menor suscetibilidade ao patógeno, comparativamente as 
Tabela 3 - Valores médios das avaliações referentes à severidade de oídio na primeira (SOP) e segunda avaliação (SOS), número de vagens por planta (NVG), número de grãos por vagem (NGV), peso de cem grãos (PCG) e rendimento (REND) de grãos de diferentes genótipos de feijão-caupi cultivados no sudeste goiano. Catalão, GO, 2008

\begin{tabular}{|c|c|c|c|c|c|c|}
\hline \multirow{3}{*}{ Cultivares } & \multicolumn{6}{|c|}{ Características avaliadas } \\
\hline & SOP & SOS & NVP & NGV & PCG & REND \\
\hline & \multicolumn{2}{|c|}{$\%$} & \multicolumn{2}{|c|}{$(\mathrm{g})$} & \multicolumn{2}{|c|}{$\left(\mathrm{kg} \mathrm{ha}^{-1}\right)$} \\
\hline BRS Guariba & $1 \mathrm{c}$ & $1 \mathrm{~d}$ & $23 \mathrm{a}$ & $11 \mathrm{~b}$ & $19 b$ & $2221 \mathrm{a}$ \\
\hline BRS Gurguéia & $1 \mathrm{c}$ & $1 \mathrm{~d}$ & $22 \mathrm{a}$ & $14 \mathrm{a}$ & $13 \mathrm{c}$ & $2196 \mathrm{a}$ \\
\hline BRS Rouxinol & $3 b$ & $5 \mathrm{~b}$ & $20 \mathrm{ab}$ & $11 \mathrm{~b}$ & $16 \mathrm{bc}$ & $1467 \mathrm{~b}$ \\
\hline BRS Marataoã & $1 \mathrm{c}$ & $1 \mathrm{~d}$ & $18 \mathrm{~b}$ & $12 \mathrm{ab}$ & $17 \mathrm{bc}$ & $1392 \mathrm{~b}$ \\
\hline Patativa & $5 \mathrm{a}$ & $7 \mathrm{a}$ & $12 \mathrm{~cd}$ & $12 \mathrm{ab}$ & $18 \mathrm{~b}$ & $881 \mathrm{c}$ \\
\hline BRS Tracuateua & $3 \mathrm{~b}$ & $5 \mathrm{~b}$ & $16 \mathrm{bc}$ & $9 \mathrm{c}$ & $27 \mathrm{a}$ & $856 \mathrm{c}$ \\
\hline BRS Milênio & $3 b$ & $5 \mathrm{~b}$ & $10 \mathrm{e}$ & $12 \mathrm{ab}$ & $19 b$ & $769 \mathrm{~cd}$ \\
\hline CE 315 & $5 \mathrm{a}$ & $7 \mathrm{a}$ & $14 \mathrm{c}$ & $9 \mathrm{c}$ & $13 \mathrm{c}$ & $675 \mathrm{~d}$ \\
\hline Média & 3 & 4 & 17 & 11 & 18 & 1307 \\
\hline C.V. (\%) & 13,33 & 14,16 & 15,24 & 7,82 & 5,47 & 19,51 \\
\hline
\end{tabular}

Médias seguidas por letras diferentes na coluna, diferem estatisticamente entre si pelo teste de Tukey, a $5 \%$ de probabilidade

demais, nas duas épocas de avaliação (Tabela 3), corroborando com as descrições da Embrapa (2008), que as classificam como moderadamente resistentes. Exceto para os genótipos CE 315 e Patativa que apresentaram porcentagens de avaliação severa na segunda avaliação, em geral os problemas com oídio não foram considerados severos, dispensando-se, assim, a utilização de qualquer controle qúmico no seu combante.

Os resultados de resistência/tolerância a oídio dos diferentes genótipos estudados são discordantes de Nechet e Halfed-Vieira (2007), que verificaram ser os genótipos de caupi do tipo prostrado menos suscetíveis à doenças, como a mela, comparativamente aos de porte ereto. Este fato indica que não há relação da arquitetura da planta com resistência/tolerância ao oídio, conforme pode ser verificado pela severidade da doença tanto em materiais classificados como semi-prostrado (CE 315) e/ou semi-ereto (Patativa) (Tabela 1). Resultado semelhante foi observado para os genótipos resistentes/tolerantes ao oídio, podendo afirmar que o grau de severidade da referida doença está em função da variabilidade genotípica do que propriamente ao hábito de crescimento da planta - ereto e/ou prostrado, ou seja, a parte fenotípica. Reações diversas de resistência das cultivares de caupi também foram notadas para viroses (LIMA et al., 2001), cercosporiose (CASTRO et al., 2003) e à sarna (BARRETO et al., 2001).

Todos os componentes do rendimento mostraramse influenciados pelos tratamentos, tendo as cultivares BRS Guariba, BRS Gurguéia e Rouxinol produzido maior número de vagens por planta. Em contrapartida, as cultivares BRS Milênio, seguida da CE 315, apresentaram o menor número de vagens por planta. Por outro lado, as cultivares BRS Gurguéia, BRS Marataoã, Patativa e BRS Milênio apresentaram maior número de grãos por vagem, enquanto a cultivar BRS Tracuateua, os maiores valores do peso de cem grãos (Tabela 3).

As cultivares BRS Guariba e BRS 17 Gurguéia destacaram-se das demais apresentando os maiores patamares de produtividades, 2.211 e $2.196 \mathrm{~kg} \mathrm{ha}^{-1}$, respectivamente (Tabela 3), demonstrando, assim, boa adaptação às condições edafoclimáticas da região do cerrado goiano. Em contrapartida, a menor produtividade de grãos foi obtida com a cultivar CE 315 (675 kg ha-1).

Com relação a produtividade média de grãos, pode-se verificar que dos oito genótipos avaliados quatro (BRS Guariba, BRS 17 Gurguéia, BRS Rouxinol e BRS Marataoã) apresentaram produtividades acima de 1.000 $\mathrm{kg} \mathrm{ha}^{-1}$ (Tabela 3), portanto, mais de três vezes superior a média nacional - $300 \mathrm{~kg} \mathrm{ha}^{-1}$ (LEITE et al., 2009), mostrando, perfeitamente, que a espécie Vigna unguiculata apresenta-se como boa opção para cultivo em áreas de cerrado na safra da seca (safrinha), devendo, para isso, buscar genótipos melhor adaptados, ou seja, com alta produtividade. Nesse contexto, a escolha de genótipos mais precoces para colheita é um fator relevante devido ao plantio de safrinha na região do cerrado, onde os materiais precoces podem escapar da falta de chuva a partir de março.

A média de rendimento obtido neste estudo (1.307 $\left.\mathrm{kg} \mathrm{ha}^{-1}\right)$ encontra-se acima das médias obtidas em outros traballhos investigativos como os de Lopes et al. 
(2001) e Matos Filho (2006), que foram, respectivamente, de 1.049 e $1.007 \mathrm{~kg} \mathrm{ha}^{-1}$, e inferior a 1.705 e $1.399 \mathrm{~kg} \mathrm{ha}^{-1}$, obtida por Bezerra et al. (2008) e Machado et al. (2008), respectivamente. Vale lembrar, contudo, que o fato da escolha de genótipos de alta capacidade produtiva em associação com outros de menor potencial contribui para o decréscimo da média de produtividade de grãos no presente estudo, mas, mesmo assim, superior a média nacional, conforme referência anterior, produzida, em grande parte, sob condição de sequeiro, em áreas concentradas das regiões áridas e semi-áridas do nordeste brasileiro.

Em adição, frisa-se que o uso da irrigação complementar realizada nas fases de florescimento e enchimento de grãos de caupi, devido a ocorrência de verânico, associado ao emprego de genótipos mais produtivos certamente contribui para o acréscimo de produtividade obtido, confirmando, dessa maneira, os relatos de Silva (2009) de que na região do cerrado comumente são obtidas produtividades da leguminosa em questão superiores a 1,0 tonelada por hectare, mesmo sem irrigação, com práticas simples e de fácil adoção pelos agricultores como plantio na época certa, emprego de população adequada de plantas, escolha de materiais com comportamento superior, dentre outras.

\section{Qualidade fisiológica de sementes}

A qualidade fisiológica de sementes apresentou comportamento diferenciado entre as diferentes cultivares testadas, conforme pode ser visto pelos resultados dos testes padrão de germinação - TPG, primeira contagem do TPG, envelhecimento acelerado, condutividade elétrica e teor de lignina $(\mathrm{P}<0,05)$. De modo geral, foi detectada boa precisão experimental nas avaliações, conforme pode ser verificado pelos coeficiente de variação, que variou de 9,71 a 15,91\% (Tabela 4).

Destaca-se, inicialmente, que o fato da colheita dos feijoeiros ter sido realizada a partir da segunda quinzena do mês de abril e, portanto, na ausência de chuva (Figura 1), contribuiu para obtenção de sementes com boa qualidade, como pode ser notado pelo percentual médio da germinação - 85\% (Tabela 4). Este resultado é concordante aos relatos de Marcos Filho (2005), que considera a falta de chuva na colheita condição "sine qua non" para obtenção de lotes de sementes de qualidade fisiológica superior. Ressalta-se, ainda, que o valor de viabilidade das sementes, exceto para BRS Tracuateua (67\%) e BRS Milênio (78\%) (Tabela 4), enquadrase dentro do percentual de germinação de sementes de grandes culturas, como o feijão-caupi, exigido para comercialização (BRASIL, 1992), que atualmente varia de valores superiores a $80-85 \%$.

$\mathrm{Na}$ Tabela 4 pode ser visto que as cultivares CE 315 , BRS Gurguéia, BRS Rouxinol, BRS Marataoã e Patativa produziram sementes de melhor qualidade fisiológica, comparativamente, a BRS Tracuateua, BRS Milênio e BRS Guariba, em todos os testes realizados. A provável explicação para esse comportamento fundamenta-se no fato de que danos mecânicos ocorridos nas sementes por ocasião da trilha, em função especialmente da cor do tegumento, concordante a outros resultados de pesquisa como de Kannenberg e Allard (1960), que constataram, em seus estudos, serem as sementes de feijão lima (Vigna lunatus L.) com tegumento branco mais sensível

Tabela 4 - Valores médios da porgentagem de plântulas normais verificadas no teste de germinação (GER), primeira contagem (PC), envelhecimento acelerado (EA), condutividade elétrica (CE) e do teor de lignina (TL) de sementes oriundas de diferentes cultivares de feijão caupi produzidas no sudeste goiano. Catalão, GO, 2008

\begin{tabular}{lllccc}
\hline \multirow{2}{*}{ Cultivares } & GER & PC & EA & CE & TL \\
\cline { 2 - 6 } & $\%$ & & $\mu \mathrm{S} \mathrm{cm}^{-1} \mathrm{~g}^{-1}$ & $\%$ & \\
\hline BRS Guariba & $80 \mathrm{~b}$ & $65 \mathrm{~b}$ & $58 \mathrm{~b}$ & $139 \mathrm{ab}$ & $1,67 \mathrm{c}$ \\
BRS Gurguéia & $88 \mathrm{ab}$ & $75 \mathrm{ab}$ & $66 \mathrm{ab}$ & $85 \mathrm{bc}$ & $1,96 \mathrm{ab}$ \\
BRS Rouxinol & $92 \mathrm{a}$ & $77 \mathrm{ab}$ & $67 \mathrm{ab}$ & $88 \mathrm{bc}$ & $1,94 \mathrm{ab}$ \\
BRS Marataoa & $88 \mathrm{ab}$ & $76 \mathrm{ab}$ & $65 \mathrm{ab}$ & $95 \mathrm{~b}$ & $1,86 \mathrm{~b}$ \\
Patativa & $89 \mathrm{ab}$ & $72 \mathrm{ab}$ & $62 \mathrm{ab}$ & $97 \mathrm{~b}$ & $1,83 \mathrm{~b}$ \\
BRS Tracuateua & $67 \mathrm{c}$ & $51 \mathrm{c}$ & $48 \mathrm{c}$ & $153 \mathrm{a}$ & $1,63 \mathrm{c}$ \\
BRS Milênio & $78 \mathrm{~b}$ & $63 \mathrm{~b}$ & $51 \mathrm{bc}$ & $142 \mathrm{ab}$ & $1,65 \mathrm{c}$ \\
CE 315 & $95 \mathrm{a}$ & $84 \mathrm{a}$ & $70 \mathrm{a}$ & $62 \mathrm{c}$ & $2,07 \mathrm{a}$ \\
\hline Média & 85 & 70 & 61 & 108 & 1,83 \\
\hline C.V. (\%) & 10,55 & 15,91 & 11,10 & 9,71 & 12,52 \\
\hline
\end{tabular}

Médias seguidas por letras diferentes na coluna, diferem estatisticamente entre si pelo teste de Tukey, a $5 \%$ de probabilidade 
a danos mecânicos em comparação com sementes de tegumento colorido, assim como em investigação de Asiedu et al. (2000), em que sementes de cultivares de feijão caupi, não pigmentadas, apresentaram mais rápida deterioração, comparativamente, as sementes pigmentadas. $\mathrm{Na}$ oportunidade, os referidos autores concluíram ser a associação coloração de tegumento e teor de lignina preponderante na determinação da resistência ou tolerância a danos no tegumento, sendo as sementes de tegumento claro, suscetível; enquanto as de tegumento escuro, resistentes. Ademais, em pesquisa recente de Santos et al. (2007), constatou-se que em sementes de soja a expressão da cor marrom no tegumento afeta positivamente a qualidade fisiológica devido a menor velocidade de embebição e a sua composição química pela maior concentração de lignina e proteína.

A relação teor de lignina/dureza do tegumento ocorre segundo Marcos Filho (2005) devido a função da lignina ser primariamente estrutural e protetora e, portanto, o baixo teor de lignina das sementes brancas pode ser apontado como a causa da sua maior suscetibilidade à danificação. Correlação positiva entre teores de lignina e resistência a dano mecânico de sementes de soja foi constatada em trabalho de Panobianco et al. (1999) e Flor et al. (2004).

Nesse contexto, acrescenta-se que o tegumento claro torna as sementes mais suscetíveis a danos mecânicos por apresentar baixa concentração de lignina, hipótese essa condizente com os resultados do teste de condutividade elétrica e teor de lignina, em que as sementes das cultivares de qualidade fisiológica inferiores como de BRS Tracuateua, BRS Milênio e BRS Guariba apresentaram maior quantidade de lixiviados no meio aquoso, com valores respectivos de 153; 142 e $139 \mu \mathrm{S} \mathrm{cm}^{-1} \mathrm{~g}^{-1}$, promovidos, certamente, pelos maiores danos sofridos pelos tegumentos das referidas cultivares durante a trilha, visto que os seus teores de lignina nestes foram menores, com percentuais respectivos de 1,63; 1,65 e $1,67 \%$ (Tabela 4).

Por outro lado, as cultivares como CE 315 $62 \mu \mathrm{S} \mathrm{cm}{ }^{-1} \mathrm{~g}^{-1}$, BRS Gurguéia - $85 \mu \mathrm{S} \mathrm{cm} \mathrm{cm}^{-1} \mathrm{~g}^{-1}$, BRS Rouxinol - $88 \mu \mathrm{S} \mathrm{cm} \mathrm{cm}^{-1} \mathrm{~g}^{-1}$ e BRS Marataoã - $95 \mu \mathrm{S}$ $\mathrm{cm}^{-1} \mathrm{~g}^{-1}$, com coloração de tegumento verde, e Patativa - $97 \mu \mathrm{S} \mathrm{cm}^{-1} \mathrm{~g}^{-1}$, de coloração marrom, teoricamente com maiores teores de lignina, apresentaram maior resistência a danos mecânicos e, portanto, com menor quantidade de íons liberados na solução.

A menor qualidade de sementes das cultivares BRS Tracuateua, BRS Milênio e BRS Guariba pode ter ocorrido devido à quantidade de reservas armazenadas, já que seus pesos de 100 grãos eram maiores, comparativamente as sementes das demais cultivares (Tabela 2), recebendo, assim, maior número de pancadas (danos mecânicos) durante a trilhagem, promovendo lesões ou danos no tegumento, endosperma e embrião. Resultados obtidos por Almeida et al. (2004) confirmam essa afirmativa em que as sementes da cultivar de feijão-caupi Rabo de Tatu, mais graúdas e de embrião ocupando posição mais superficial, foram mais sensíveis a quebras ou injúrias mecânicas, em comparação com as sementes menores das cultivar Cedinha.

Para Peske et al. (2006), as injúrias mecânicas durante as fases de colheita, trilha, beneficiamento, armazenamento e transporte ocorrem comumente e são, praticamente, inevitáveis. No caso da semente de feijão-caupi tem-se um agravante pelo fato desta ser particularmente suscetível à danificação de natureza mecânica, uma vez que o eixo embrionário está situado sob tegumento pouco espesso, que praticamente não oferece proteção. Dessa forma, estudos sobre a qualidade de sementes produzidas deve ser uma preocupação dos programas de melhoramento atuantes com a espécie Vigna unguiculata L.

\section{Conclusões}

1. Considerando as condições de manejo disponível (uso de irrigação complementar) para a cultura do feijãocaupi, as cultivares BRS Guariba e BRS Gurguéia são de melhor desempenho para a safra da seca na região do cerrado goiano.

2. A qualidade fisiológica de sementes de feijão-caupi é influênciada pelas cultivares.

3. As cultivares de feijão-caupi CE 315, BRS Gurguéia, BRS Rouxinol, BRS Marataoã e Patativa produzem sementes de melhor qualidade fisiológica, em comparação com as cultivares BRS Tracuateua, BRS Milênio e BRS Guariba.

\section{Referencias}

ALMEIDA, F. A. C. et al. Danos mecânicos em sementes de feijão Vigna, causados pelas operações da unidade de beneficiamento. Revista Brasileira de Engenharia Agrícola e Ambiental, v. 08, n. 02/03, p. 254-259, 2004.

ASIEDU, E. A. et al. Cowpea seed coat chemical analysis in relation to Storage seed quality. African Crop Science Journal, v. 08 , n. 03 , p. $283-294,2000$.

BARRETO, P. D. et al. Reação de genótipos de Vigna unguiculata à sarna e efeito da doença sobre componentes de produção. Fitopatologia Brasileira, v. 26, n. 01, p. 5-9, 2001.

BEZERRA, A. A. C. et al. Morfologia e produção de grãos em linhagens modernas de feijão-caupi submetidas a diferentes 
densidades populacionais. Revista de Biologia e Ciências da Terra, v. 08, n. 01, p. 85-92, 2008.

BRASIL. Ministério da Agricultura e Reforma Agrária. Regras para análise de sementes. Brasília: MARA/SNDA/DNDV/ CLV, 1992. 365 p.

CARDOSO, M. J.; RIBEIRO, V. Q. Desempenho agronômico do feijão-caupi, cv. Rouxinol, em função de espaçamentos entre linhas e densidades de plantas sob regime de sequeiro. Revista Ciência Agronômica, v. 37, n. 01, p. 102-105, 2006.

CASTRO, N. R. et al. Herança da resistência genética do caupi à cercosporiose. Fitopatologia Brasileira, v. 28, n. 03, p. 552-554, 2003.

DAMIÃO FILHO, C. F; MÔRO, F. V. Morfologia externa das espermatófitas. Jaboticabal: FUNEP, 2001. 101 p.

EMPRESA BRASILEIRA DE PESQUISA AGROPECUÁRIA (EMBRAPA). Publicações: folders. 2008. Disponível em: $<$ http://www.cpamm.embrapa.br/>. Acesso em: 14 set. 2008.

FLOR, E. P. O. et al. Avaliação de danos mecânicos em sementes de soja por meio da análise de imagens. Revista Brasileira de Sementes, v. 26, n. 01, p. 68-76, 2004.

KANNENBERG, L. W.; ALLARD, R. W. An association between pigment and lignin formation in the seed coat of the Lima bean. Crop Science, v. 04, n. 05, p. 621-622, 1960.

KRZYZANOWSKI, F. C. et al. Vigor de sementes: conceitos e testes. Londrina: Abrates, 1999. 242 p.

LEITE, L. F. C. et al. Nodulação e produtividade de grãos do feijão-caupi em resposta ao molibdênio. Revista Ciência Agronômica, v. 40, n. 04, p. 492-497, 2009.

LIMA, J. A. A. et al. Fontes de resistência múltipla em feijão-caupi a vírus das famílias Bromoviridae, Comoviridae e Potyviridae. Fitopatologia Brasileira, v. 26, p. 521, 2001. Suplemento.

LOPES, A. C. A. et al. Variabilidade e correlações entre caracteres agronômicos em caupi (Vigna unguiculata). Pesquisa Agropecuária Brasileira, v. 36, n. 02, p. 515-20, 2001.

MACHADO, C. F. et al. Identificação de genótipos de feijão-caupi quanto à precocidade, arquitetura da planta $\mathrm{e}$ produtividade de grãos. Revista Ciência Agronômica, v. 39, n. 01, p. 114-123, 2008.
MARCOS FILHO. Fisiologia de sementes de espécies cultivadas. Jaboticabal: Funep, 2005. 546 p.

MATOS FILHO, C. H. A. Análise genética de caracteres relacionadas a arquitetura de planta em feijão-caupi (Vigna unguiculata (L.) Walp.) 2006. 57 f. Dissertação (Mestrado em Produção Vegetal) - Universidade Federal do Piauí, Teresina.

NECHET, K. L.; HALFELD-VIEIRA. B. A. Reação de cultivares de feijão-caupi à mela (Rhizoctonia solani) em Roraima. Fitopatologia Brasileira, v. 32, n. 05, p. 424-427, 2007.

OLIVEIRA, A. P. et al. Avaliação de linhagens e cultivares de feijão-caupi, em Areias, PB. Horticultura Brasileira, v. 20, n. 02, p. 180-182, 2002.

PANOBIANCO, M. et al. Electrical conductivity of soybean seed and correlation with seed coat lignin content. Seed Science and Technology, v. 27, n. 03, p. 945-949, 1999.

PESKE, S. T. et al. Sementes: fundamentos científicos e tecnológicos. Pelotas: UFPel, 2006. 472 p.

ROCHA, M. M. et al. Estimativas de parâmetros genéticos em genótipos de feijão-caupi de tegumento branco. Revista Cientifica Rural, v. 08, n. 01, 134-141, 2003.

SANTOS, E. L. et al. Qualidade físiológica e composição química das sementes de soja com variação na cor do tegumento. Revista Brasileira de Sementes, v. 29, n. 01, p. 20-26, 2007.

SILVA, K. J. D. e. Estatística da produção de feijão-caupi. 2009. Disponível em: $<$ http://www.portaldoagronegocio.com. br/conteudo.php?id=34241>. Acesso em: 03 mar. 2010.

TEÓFILO, E. M. et al. Potencial fisiológicos de sementes de feijão caupi produzidas em duas regiões do estado do Ceará. Revista Ciência Agronômica, v. 39, n. 03, p. 443-448, 2008.

VAN SOEST, P. J.; WINE, R. H. Determination of lignin and cellulose in acid detergent fiber with permanganate. Journal of the Association of Official Agricultural Chemists, v. 51, p. 780-785, 1968 .

VIEIRA, R. F. et al. Comportamento do feijão-fradinho na primavera-verão na Zona da Mata de Minas Gerais. Pesquisa Agropecuária Brasileira, v. 35, n. 07, p. 1359-1365, 2000.

VIEIRA, R. F. Comportamento de cultivares de caupi do tipo fradinho em Leopoldina, Minas Gerais. Revista Ceres, v. 48, n. 280, p. 729-733, 2001. 